\title{
Role of free testosterone levels in patients with metastatic castration-resistant prostate cancer receiving second-line therapy
}

\author{
CHRISTOPH A. VON KLOT ${ }^{1}$, MARKUS A. KUCZYK ${ }^{1}$, ALENA BOEKER ${ }^{1}$, CHRISTOPH REUTER ${ }^{2}$, \\ FLORIAN IMKAMP ${ }^{1}$, THOMAS R.W. HERRMANN ${ }^{1}$, HOSSEIN TEZVAL $^{1}$, MARIO W. KRAMER ${ }^{3}$, \\ SVEN PERNER ${ }^{4}$ and AXEL S. MERSEBURGER ${ }^{3}$
}

\begin{abstract}
Departments of ${ }^{1}$ Urology and Urological Oncology and ${ }^{2}$ Hematology and Oncology, Hannover Medical School, D-30625 Hannover; ${ }^{3}$ Department of Urology, Campus Luebeck, University Hospital Schleswig-Holstein, D-24105 Luebeck;

${ }^{4}$ Pathology Network of the University Hospital of Luebeck and Leibniz Research Center, D-23528 Borstel, Germany
\end{abstract}

Received April 18, 2016; Accepted July 7, 2016

DOI: $10.3892 / \mathrm{ol} .2016 .5392$

\begin{abstract}
A range of new treatment options has recently become available for patients with advanced metastatic castration-resistant prostate cancer (mCRPC). Androgen deprivation therapy (ADT) with luteinizing hormone-releasing hormone is continued when performing chemotherapy or androgen deprivation with new second-generation therapeutic agents such as enzalutamide or abiraterone acetate. Despite the fact that free testosterone (FT) is the biologically active form, it is common practice that androgen suppression is monitored via total testosterone levels only. The aim of the present study was to evaluate the role of FT as a prognostic biomarker for cancer-specific survival (CSS) and its feasibility as an ADT monitoring biomarker in patients with mCRPC for the first time. The requirement for continued ADT in mCRPC patients is discussed within the basis of the current literature. A total of 34 patients with continuous measurements of FT levels and mCRPC status underwent therapy with docetaxel, abiraterone acetate, enzalutamide, cabozantinib, carboplatin or cabazitaxel. Data were obtained from the Departments of Urology and Urological Oncology, Hannover Medical School (Hannover, Germany) between March 2009 and April 2014. A cutoff point of $0.5 \mathrm{pg} / \mathrm{ml}$ was used to discriminate between patients according to FT levels. Statistical evaluation of CSS was performed by applying Kaplan Meier survival estimates, multivariate Cox regression analyses and log-rank tests. The median age of all 34 patients was 72 years (range, 51-86 years). The mean follow-up interval was 16.1 months (range, 0.7-55.6 months). Despite the fact
\end{abstract}

Correspondence to: Dr Christoph A. von Klot, Department of Urology and Urological Oncology, Hannover Medical School, Carl-Neuberg-Straße 1, D-30625 Hannover, Germany

E-mail: klot.christoph@mh-hannover.de

Key words: free testosterone, metastatic castration-resistant prostate cancer, androgen deprivation therapy, luteinizing hormone-releasing hormone, abiraterone acetate, enzalutamide that all patients were undergoing androgen deprivation, the mean serum FT levels for each patient varied; the mean FT concentration in the cohort was $0.328 \mathrm{pg} / \mathrm{ml}$, ranging from 0.01-9.1 pg/ml. A notable difference with regard to CSS was observed for patients with regard to serum FT concentration; CSS was significantly longer for patients with a serum FT level below the cutoff level (43.6 vs. 17.3 months, respectively, $\mathrm{P}=0.0063$ ). Upon multivariate Cox regression analysis, the mean FT concentration during treatment remained a significant prognostic factor for CSS (hazard ratio, 1.22; 95\% confidence interval, 1.03-1.43; $\mathrm{P}=0.0182$ ). In conclusion, in patients with mCRPC, the serum FT level is a strong predictor of CSS in patients under therapy with second-line anti-hormonal therapeutic medication and chemotherapy. It may be concluded that FT levels should be included into the routine control of androgen suppression while under treatment with ADT and second-generation hormonal therapy.

\section{Introduction}

Despite various established and curatively intended therapeutic regimens, new options for chemotherapy and novel modes of androgen deprivation, $>70,000$ patients succumb to prostate cancer each year in Europe (1). Huggins et al (2) described the dependence of prostate cancer on androgen levels in 1941. This finding marked the beginning of systemic and targeted treatment for advanced and metastasized adenocarcinoma of the prostate (3). To date, the backbone for the initial systemic treatment of prostate cancer is androgen deprivation therapy (ADT) (4). Androgen suppression, however, is associated with adverse clinical effects for the patient (5) and invariably leads to the resistance to androgen deprivation and the progression of the disease over time (6). The term 'hormone-refractory' or '-resistant' prostate cancer was used to describe progressing prostate cancer under ADT, which appeared to grow independently from androgen manipulation. With today's understanding of prostate tumor biology, the term has eventually been adapted to 'castration-resistant prostate cancer' (CRPC), indicating that progression remains driven by androgen signaling at the castration-resistant stage. CRPC is the current and recommended term established by 
the Prostate Cancer Working Group 2 (PCWG 2) (7). The new understanding of castration-resistant disease has led to the development and implementation of second-generation androgen ablative regimens, the most established of which thus far are the two orally administered substances abiraterone acetate and enzalutamide $(8,9)$. Aside from advances in hormone ablative therapy, chemotherapeutic options have also expanded, including the introduction of cabazitaxel for the treatment of docetaxel-resistant prostate cancer, which showed a survival benefit in the preceding TROPIC trial (10). Prostate cancer at the metastatic CRPC (mCRPC) stage progresses apparently independent of conventional ADT. However, it is common practice that ADT is continued when switching to chemotherapy or second-line hormone manipulation with abiraterone acetate or enzalutamide. The monitoring of androgen suppression is normally achieved by measuring total testosterone levels, however, the biologically active androgen is free testosterone (FT), which only comprises $1-2 \%$ of total testosterone $(11,12)$.

Discontinuation of luteinizing hormone-releasing hormone (LHRH) therapy would reduce treatment costs, as well as the incidence of adverse events attributed to LHRH therapy (5). The question of whether conventional ADT may be omitted in progressive prostate cancer remains under debate. This question will be addressed for abiraterone acetate in the ongoing SPARE trial (13). To date, there is no reliable clinical data on patients with second-generation ADT and discontinuation of LHRH-analogue therapy. The present study analyzed a series of patients with advanced $\mathrm{mCRPC}$ receiving second-line chemotherapy and/or second generation ADT with regard to FT serum levels and evaluated the effect of FT on cancer-specific survival (CSS).

\section{Patients and methods}

Patient selection. Patients were followed up between March 2009 and April 2014. Patients were deemed eligible for this retrospective study is they had histologically confirmed mCRPC. All patients were androgen ablated with an LHRH agonist, with the exception of 2 patients who underwent a bilateral subcapsular orchiectomy. ADT was continued throughout the follow-up. FT represents the biologically active fraction of total testosterone (11). Out of 4,642 patients from the Departments of Urology and Urological Oncology, Hannover Medical School (Hannover, Germany) database, only 34 exhibited CRPC and were monitored with the inclusion of FT level. Levels of FT were measured in the morning. Patients receiving $1,000 \mathrm{mg} /$ day abiraterone acetate received concomitant steroid medication with $10 \mathrm{mg}$ prednisolone per day. The Eastern Cooperative Oncology Group (ECOG) status at the beginning of the follow-up was 0 for all patients (14), with the exception of 2 (1 patient with an ECOG score of 1 and 1 patient with an ECOG score of 2). Patients received abiraterone acetate during the compassionate use program, which was approved by the Hannover Medical School Ethics Committee (Hannover, Germany). Carboplatin AUC5 plus docetaxel at a dose of $35 \mathrm{mg} / \mathrm{m}^{2}$ was used as a salvage chemotherapy option after failure of docetaxel chemotherapy (15). Cabozantinib was administered to patients participating in the COMET-1 trial (phase III, cabozantinib vs. prednisone).
Prostate-specific antigen (PSA) measurements and testing of FT concentration was performed at Hannover Medical School exclusively.

Laboratory measurements. For the measurement of FT concentration, an enzyme immunoassay was applied for the quantitative determination of FT (IBL International GmbH, Hamburg, Germany). To determine the serum PSA concentration, an Electrochemiluminescence Immunoassay (Cobas ${ }^{\circledR}$ 6000, Roche Diagnostics, Rotkreuz, Switzerland) was used. The PCWG-2 criteria were applied to define the progression of the cancer (7). Change of therapy under follow-up was allowed on progression of the disease while continuing constant androgen ablative therapy (7).

Statistical analysis. Survival rates were estimated using the Kaplan-Meier method. The log-rank test was applied for comparing survival between patients with different mean FT concentrations. Hazard ratios for the prediction of CSS were calculated using multivariate Cox regression with Efron's approximation. Likelihood ratio-, Wald- and score (log-rank) tests were applied to test the effect of covariates of the Cox regression model. Proportionality of all predictor variables were tested using Pearson's product-moment correlation between the scaled Schoenfeld residuals and time for each covariate. All mortalities during observation were attributable to the underlying prostate cancer disease, hence no patient had to be censored for competing causes of mortality. $\mathrm{P}<0.05$ was considered to indicate a statistically significant difference. Statistical analyses and graphical illustrations were performed using R statistical software ( $\mathrm{R}$ version 3.0.3; R Foundation for Statistical Computing, Vienna, Austria). Patient characteristics are depicted in Table I.

Ethics and approval. The present study was performed in accordance with all ethical standards laid down in the 1964 Declaration of Helsinki and its later amendments. Ethics board approval was obtained for this observational retrospective study. All patient data was anonymized prior to statistical analysis. No additional data was created nor used aside from the retrospective evaluation of our database.

\section{Results}

In total, 34 patients with mCRPC were eligible and had sufficient follow-up of serum FT values. The median follow-up time was 16.1 months (range, 0.7-55.6 months) and the median patient age was 72 years (range, 51-86 years). The mean FT concentration in the cohort was $0.328 \mathrm{pg} / \mathrm{ml}$. Despite the fact that all patients were under continuous ADT, mean FT levels for each patient varied, ranging from $0.01-9.1 \mathrm{pg} / \mathrm{ml}$, with a variance of $0.4 \mathrm{pg} / \mathrm{ml}$. A total of 17 patients succumbed during follow-up. Median survival over all patients according to Kaplan-Meier survival estimation was 32.8 months [ $95 \%$ confidence interval (CI), 17-not available (NA)], as shown in Fig. 1. Mean PSA correlated with CSS (log-rank test, $\mathrm{P}=0.0063$ ), which was expected since all patients succumbed during the progression of the disease. Mean PSA was $264.2 \mathrm{ng} / \mathrm{ml}$ (range, 1.9-1,486.2 ng/ml). All mortalities were associated with a rising PSA at the end of follow-up. The mean PSA value was associated with mortality 
Table I. Patient characteristics: Pathology and previous treatment.

\begin{tabular}{|c|c|}
\hline Characteristic & Value \\
\hline Patients, n $(\%)$ & $34(100.0)$ \\
\hline Median age (range), years & $72(51-86)$ \\
\hline \multicolumn{2}{|l|}{ Primary therapy, n (\%) } \\
\hline Retropubic prostatectomy & $19(55.9)$ \\
\hline Laparoscopic prostatectomy & $2(5.9)$ \\
\hline External beam radiation & $3(8.8)$ \\
\hline LDR brachytherapy & $1(2.9)$ \\
\hline No primary therapy & $8(23.5)$ \\
\hline NA & $1(2.9)$ \\
\hline \multicolumn{2}{|l|}{ TNM stage, n (\%) } \\
\hline $\mathrm{T} 2 \mathrm{a}$ & $1(2.9)$ \\
\hline $\mathrm{T} 2 \mathrm{~b}$ & $1(2.9)$ \\
\hline $\mathrm{T} 2 \mathrm{c}$ & $2(5.9)$ \\
\hline $\mathrm{T} 3 \mathrm{a}$ & $4(11.8)$ \\
\hline $\mathrm{T} 3 \mathrm{~b}$ & $13(38.2)$ \\
\hline $\mathrm{T} 4 \mathrm{a}, \mathrm{b}$ & $4(11.8)$ \\
\hline NA & $9(26.5)$ \\
\hline \multicolumn{2}{|l|}{ Gleason score, n (\%) } \\
\hline$\leq 6$ & $1(2.9)$ \\
\hline 7 & $10(29.4)$ \\
\hline 8 & $12(35.3)$ \\
\hline 9 & $5(14.7)$ \\
\hline 10 & $3(8.8)$ \\
\hline NA & $3(8.8)$ \\
\hline \multicolumn{2}{|l|}{ Hormonal therapy, n (\%) } \\
\hline Orchiectomy & $2(5.9)$ \\
\hline ADT & $1(2.9)$ \\
\hline $\mathrm{CAB}$ & $27(79.4)$ \\
\hline Abiraterone & $25(73.5)$ \\
\hline Enzalutamide & $24(70.6)$ \\
\hline \multicolumn{2}{|l|}{ Chemotherapy, n (\%) } \\
\hline Docetaxel & $31(91.2)$ \\
\hline Carboplatin+docetaxel & $19(55.9)$ \\
\hline Cabazitaxel & $8(23.5)$ \\
\hline Cabozantinib & $3(8.8)$ \\
\hline Mean PSA (range), pg/ml & $182.8(1.9-1486.2)$ \\
\hline
\end{tabular}

NA, data not available; ADT, androgen deprivation therapy; CAB, complete androgen blockade; PSA, prostate-specific antigen; TNM, tumor-node-metastasis.

in the multivariate Cox model for patients with a mean PSA of $\geq 200 \mathrm{ng} / \mathrm{ml}$ [hazard ratio (HR), 4.6; $95 \% \mathrm{CI}, 1.1-19.3 ; \mathrm{P}=0.0354$ ). A notable difference with regard to CSS was observed for patients with FT concentrations below and above $0.5 \mathrm{pg} / \mathrm{ml}$ : Median survival for patients with a FT level below and above the cutoff were 43.6 months (range, 31.5-NA months) and 17.3 months (range, 12.7-NA months), respectively (log-rank test, $\mathrm{P}=0.0063$ ). The Kaplan-Meier estimation of survival according to FT serum concentration is depicted in Fig. 2. When
Table II. HRs, 95\% CIs and P-values for the multivariate Cox regression analysis on cancer-specific survival for patients with metastatic castration-resistant prostate cancer.

\begin{tabular}{llll}
\hline Variable & HR & $95 \%$ CI & P-value \\
\hline FT & 1.22 & $1.03-1.43$ & $0.0182^{\mathrm{a}}$ \\
PSA & 4.63 & $1.11-19.28$ & $0.0354^{\mathrm{a}}$ \\
Age & 1.03 & $0.95-1.12$ & 0.4293 \\
Gleason score & 1.35 & $0.69-2.66$ & 0.3854 \\
ECOG & 1.08 & $0.15-7.6$ & 0.9391 \\
\hline
\end{tabular}

${ }^{\mathrm{a}} \mathrm{P}<0.05$. FT, free testosterone; PSA, prostate-specific antigen; ECOG, Eastern Cooperative Oncology Group; CI, confidence interval; HR, hazard ratio.

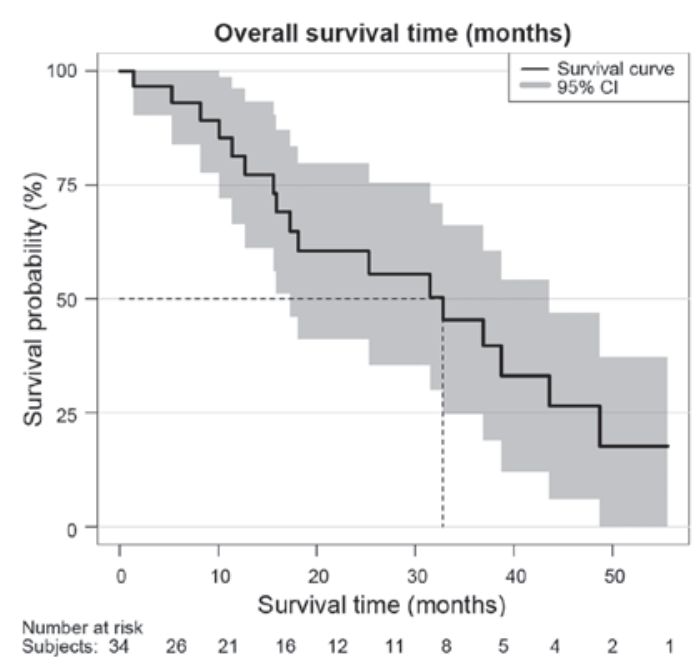

Figure 1. Kaplan Meier estimation of survival based on cancer-specific survival data of all 34 patients with metastatic castration-resistant prostate cancer, showing a limited median life expectancy of 32.8 months (range, 17-not available). CI, confidence interval.

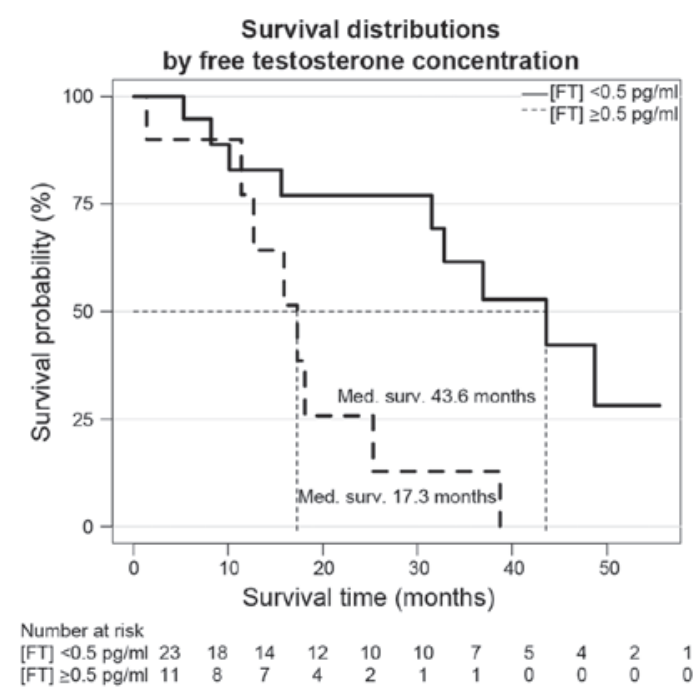

Figure 2. Kaplan Meier survival estimation of all patients according to FT level; dichotomization at a cutoff at $0.5 \mathrm{pg} / \mathrm{ml}$ was applied. The median FT concentration was $0.33 \mathrm{pg} / \mathrm{ml}$. Median survival time for patients with FT levels below and above the cutoff were 43.6 and 17.3 months, respectively (log-rank test, $\mathrm{P}=0.0063$ ). FT, free testosterone. 


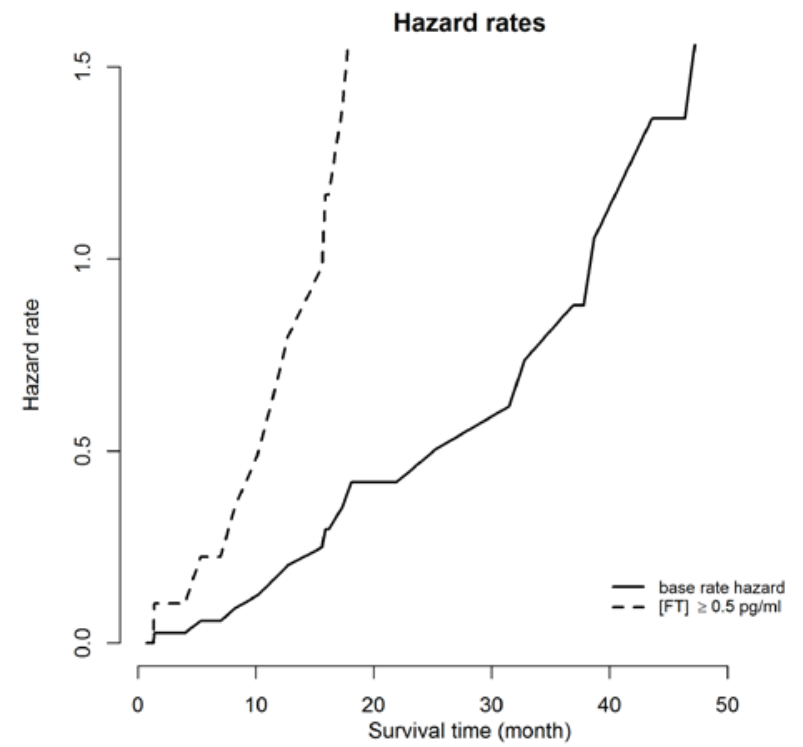

Figure 3. Base rate hazard and hazard rate for patients with a mean FT concentration. Cutoff, $\geq 0.5 \mathrm{pg} / \mathrm{ml}$. FT, free testosterone.

applying multivariate Cox regression analysis, the HR for the risk of mortality for patients with FT concentrations $\geq 0.5 \mathrm{pg} / \mathrm{ml}$ was 1.2 (95\% CI, 1-1.4; $\mathrm{P}=0.0182)$; hazard rates and HRs are depicted in Figs. 3 and 4, respectively. For the covariates of patient age, primary Gleason score and ECOG performance status $(14,16,17)$, there was no significant statistical association for the risk of mortality $(\mathrm{P}=0.4293, \mathrm{P}=0.3854$ and $\mathrm{P}=0.9391$, respectively), as shown in Table II.

\section{Discussion}

When prostate cancer progresses apparently independent of conventional hormonal manipulation, the question arises as to whether a conventional ADT regimen should be continued during second-line ADT. Abiraterone acetate and enzalutamide exert their effects on intracellular signaling by more substantial and firm effects on androgen biosynthesis and androgen receptor binding than their predecessors: LHRH analogues cause a downregulation of LHRH receptors in the pituitary gland, thereby decreasing the release of gonadotropins and consecutively the production of testosterone; however, this effect on prostate neoplastic cells is confined to the hypothalamic-pituitary-gonadal axis (18). Abiraterone decreases serum testosterone and androgen levels by inhibiting $17 \alpha$-hydroxylase/C17,20-lyase in steroid biosynthesis, and is not only limited to the testicular Leydig cells, but is also exerting its effect in the adrenal gland and in prostate cancer cells (19). First-generation non-steroidal anti-androgens, including flutamide and bicalutamide, block the androgen receptor, thereby inhibiting intracellular signaling. Enzalutamide has a higher binding affinity to the androgen-receptor, and it not only acts competitively at the receptor level, but also blocks the activation of androgen-responsive genes and inhibits the preceding translocation of the homodimerized receptor-ligand (20). Applying LHRH analogues or non-steroidal anti-androgens while administering abiraterone acetate or enzalutamide may therefore appear redundant when considering modes of action for these substances. The concept of continued conventional ADT and serum testosterone level monitoring with regard to clinical parameters and overall survival (OS), originates from a notable study by Perachino et al, showing a clear association between OS and serum testosterone levels measured 6 months after initiation of ADT (21). The study was based on previous results of a study by Morote et al, in which it was deduced that from a cohort of 73 patients, $25 \%$ of all men being treated with LHRH-depot injection exhibited testosterone levels higher than the formerly recommended serum level of $0.5 \mathrm{ng} / \mathrm{ml}$. The study found a direct correlation between 'androgen-independent' (originally used expression) progression and serum testosterone levels. It was also able to show that breakthrough increases of testosterone levels during LHRH agonist therapy exhibited a markedly negative effect on 'androgen-independent' progression. The mean survival time, free from 'androgen-independent' progression, was 137 months for the subgroup of patients without breakthrough increases of testosterone and it decreased to 88 months for patients with breakthrough increases of $>32 \mathrm{ng} / \mathrm{dl}$ (22).

The study by Byar was also able to show a contributing effect of insufficient androgen suppression on overall mortality, however, this effect was observed with the administration of diethylstilbestrol (23), and unlike our current study, not with LHRH analogues in conjunction with abiraterone acetate or enzalutamide.

Other retrospective studies evaluating the positive effects of continued ADT therapy in patients with CRPC have also shown survival advantages for patients who sustained LHRH analogue therapy $(24,25)$. These findings clearly emphasize the requirement for laboratory monitoring of ADT therapy, however, the aforementioned studies were undertaken a long time prior to the advent of second-line anti-androgens. Also, the previously mentioned studies by Morote et al (22) and others, used total testosterone, which is easier to measure than FT. In the current study, an emphasis was placed on FT, which is the active fraction responsible for biological activity (11). Notably, there is not yet much data on FT with regard to prostate cancer.

A more recent finding that does potentially support the continuation of LHRH therapy, including serum testosterone measurements on a regular schedule, was derived from the COU-AA-301 study itself (26). Data from the trial, initially comparing the efficacy of abiraterone acetate plus low-dose prednisone versus prednisone only, was subsequently analyzed with regard to androgen dynamics in correlation with serum PSA: In an ultra-sensitive assay, PSA measurements showed a reduction to undetectable levels in $47 \%$ of patients in the abiraterone arm, while none of the patients continuing regular androgen deprivation exhibited serum testosterone levels below the detection threshold. The study compared androgen levels with radiographic progression-free survival and time to PSA progression, but found no significant correlation. However, unlike the present study, the measurements were timed exclusively 12 weeks after the initiation of therapy. Additionally, the focus was on total testosterone concentration and not FT levels. Nonetheless, these findings show that inadequate androgen suppression may and does occur in patients with inhibition of the hypothalamic-pituitary-gonadal axis, even when combined with 
A

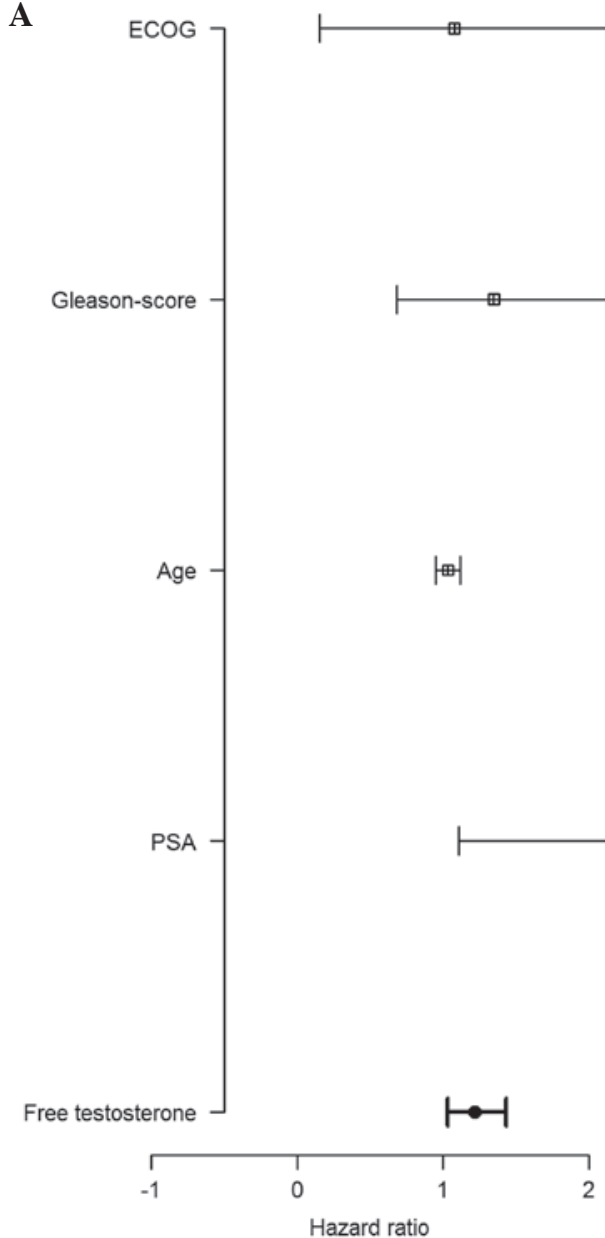

$\mathbf{B}$

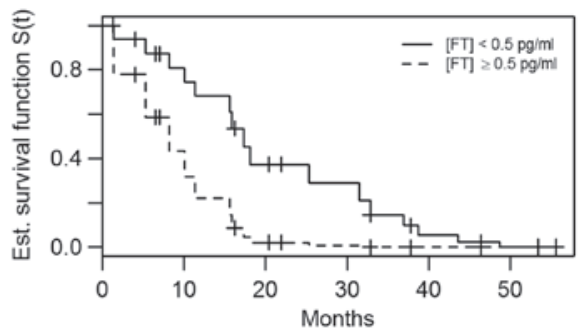

C

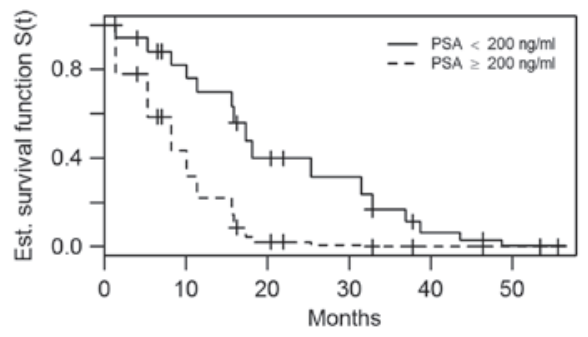

D

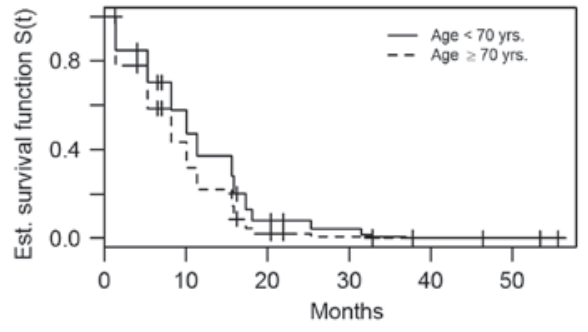

Figure 4. (A) Forest plot of hazard ratios for cancer-specific survival and corresponding $95 \%$ confidence intervals. Estimated survival function from multivariate Cox regression model for (B) FT concentration, (C) PSA $\geq 200 \mathrm{ng} / \mathrm{ml}$ and (D) patient age. FT, free testosterone; PSA, prostate-specific antigen; ECOG, Eastern Cooperative Oncology Group.

inhibitors of precursor steroid biosynthesis (27). Notably, $13-42 \%$ of patients under therapy with LHRH analogues fail to reach serum testosterone levels of $<0.5 \mathrm{ng} / \mathrm{ml}$ (28). These involuntary elevations of serum testosterone may provide an insight as to what extent circulating androgens play a role in the advanced $\mathrm{mCRPC}$ setting when next-generation ADT is in place. The reason for the significant increases of androgen levels under therapy is not fully understood. Certain men may experience a surge in serum testosterone concentration while under long-term therapy with LHRH analogues. This phenomenon was previously described as the 'acute-on-chronic response' (29). Also, obese patients tend to have higher testosterone concentration levels under LHRH therapy than men with a normal body mass index (30). Other reasons for insufficient androgen suppression are a faulty preparation of the LHRH depot injection or inadvertent discontinuation of therapy. While FT and total testosterone concentrations can frequently be assessed, the aforementioned reasons for insufficient androgen suppression cannot adequately be identified or monitored. The present study showed a variance in FT serum concentration. However, it did not provide a clear explanation for these surges in FT levels. One possible incentive for the continuation of conventional ADT may lay in the assumption of a broader mode of therapy in the castration-resistant state. The mechanisms that lead to the castration-resistant state are numerous and have been subjected to extensive research in the past. Intracellular cell signaling promoting growth and tumor progression may continue by means of 'bypass' or 'outlaw' pathways, even without the binding of the androgen receptor ligand. One example for these mechanisms is the expression of B-cell lymphoma 2 , which is a critical anti-apoptotic protein in CRPC and prostate cancer in general (31). Another example is the Akt signaling cascade (32) or the overexpression of human epidermal growth factor receptor-2/neu tyrosine kinase. The latter is able to boost prostate cancer growth and androgen receptor signaling independently of the androgen ligand binding to the receptor (33). These models for the alternate activation of prostate cancer cells appear to be independent of androgen signaling and do not give a clear justification for the continuation of LHRH therapy in the mCRPC state. Androgen receptor splice variant-7 (AR-V7), presented at the 2014 Genitourinary Cancer Symposium annual meeting, lacks the ligand-binding domain for enzalutamide, but it remains active as a transcription factor. PSA response rates were $0 \%$ for abiraterone and enzalutamide in patients with the AR-V7 splice variant, which directly translated into shorter progression-free survival times (34). 
However, these data do neither support nor negate the beneficial effect of an ongoing conventional ADT while starting with enzalutamide or abiraterone acetate. Free androgen levels appear to significantly affect CSS, as shown in the current study. This indicates that progression in a cohort of patients with mCRPC is not merely driven by escape mechanisms and resistance completely independent of androgen signaling, but is dependent on serum FT levels, even with the combination of conventional ADT and second-generation hormone manipulation. This finding can be explained through clonal heterogeneity or by resistance mechanisms that rely on FT, such as androgen receptor overexpression $(35,36)$. We hypothesize that one possible argument in favor for continuing conventional ADT, while administering enzalutamide or abiraterone acetate, may be an overlap in treatment that could potentially reduce the risk of FT surges due to accidental pauses of treatment. One of the most notable studies with regard to LHRH therapy during second-line hormonal manipulation was conducted by Pinski et al, which showed that $\mathrm{LH}$ receptors exist on prostate cancer cells and stimulate cancer growth by increasing intrinsic steroidogenesis (37). This finding would be an argument in favor for the continuation of conventional LHRH analogue therapy. The inhibition of steroid biosynthesis in addition to LHRH analogue therapy is not new; it was used even prior to the advent of abiraterone acetate, when ketoconazole was combined with complete androgen blockade resulting in a markedly lower testosterone concentration when compared to complete androgen blockade alone (38). Probably the most important argument in favor of the continued use of LHRH analogue therapy in the mCRPC state is, however, the lack of clinical studies with regard to survival. The current study, therefore, may represent one of the first pieces of clinical evidence on the topic.

The current study was limited by its retrospective design and the heterogeneity of treatments that, however, reflect the therapeutic reality of patients with mCRPC today.

In conclusion, patients with advanced mCRPC who have progressed under conservative ADT have FT as a significant predictor of CSS, even in the sequence of second-generation ADT (abiraterone acetate or enzalutamide) and chemotherapy. The present findings support the recommendation that LHRH-analogue therapy and measurements of androgen suppression on a regular basis should not be omitted in this setting.

\section{References}

1. Malvezzi M, Bertuccio P, Levi F, La Vecchia C and Negri E: European cancer mortality predictions for the year 2013. Ann Oncol 24: 792-800, 2013.

2. Huggins C, Stevens RE and Hodges CV: Studies on prostate cancer. II. The effects of castration on advanced carcinoma of the prostate gland. Arch Surg 43: 209-223, 1941.

3. Walsh PC: Physiologic basis for hormonal therapy in carcinoma of the prostate. Urol Clin North Am 2: 125-140, 1975.

4. Merseburger AS, Hammerer $P$, Rozet $F$, Roumeguère T, Caffo O, da Silva FC and Alcaraz A: Androgen deprivation therapy in castrate-resistant prostate cancer: How important is GnRH agonist backbone therapy? World J Urol 33: 1079-1085, 2015.

5. Faris JE and Smith MR: Metabolic sequelae associated with androgen deprivation therapy for prostate cancer. Curr Opin Endocrinol Diabetes Obes 17: 240-246, 2010.
6. Heidenreich A, Bastian PJ, Bellmunt J, Bolla M, Joniau S, van der Kwast T, Mason M, Matveev V, Wiegel T, Zattoni F, et al: EAU guidelines on prostate cancer. Part II: Treatment of advanced, relapsing and castration-resistant prostate cancer. Eur Urol 65: 467-479, 2014.

7. Scher HI, Halabi S, Tannock I, Morris M, Sternberg CN, Carducci MA, Eisenberger MA, Higano C, Bubley GJ, Dreicer R, et al: Design and end points of clinical trials for patients with progressive prostate cancer and castrate levels of testosterone: Recommendations of the prostate cancer clinical trials working group. J Clin Oncol 26: 1148-1159, 2008.

8. Fizazi K, Scher HI, Molina A, Logothetis CJ, Chi KN, Jones RJ, Staffurth JN, North S, Vogelzang NJ, Saad F, et al: Abiraterone acetate for treatment of metastatic castration-resistant prostate cancer: Final overall survival analysis of the COU-AA-301 randomised, double-blind, placebo-controlled phase 3 study. Lancet Oncol 13: 983-992, 2012.

9. Ryan CJ, Smith MR, de Bono JS, Molina A, Logothetis CJ, de Souza P, Fizazi K, Mainwaring P, Piulats JM, Ng S, et al: Abiraterone in metastatic prostate cancer without previous chemotherapy. N Engl J Med 368: 138-148, 2013.

10. de Bono JS, Oudard S, Ozguroglu M, Hansen S, Machiels JP, Kocak I, Gravis G, Bodrogi I, Mackenzie MJ, Shen L, et al: Prednisone plus cabazitaxel or mitoxantrone for metastatic castration-resistant prostate cancer progressing after docetaxel treatment: A randomised open-label trial. Lancet 376: 1147-1154, 2010.

11. Mendel CM: The free hormone hypothesis: A physiologically based mathematical model. Endocr Rev 10: 232-274, 1989.

12. Moreno SA, Shyam A and Morgentaler A: Comparison of free testosterone results by analog radioimmunoassay and calculated free testosterone in an ambulatory clinical population. J Sex Med 7: 1948-1953, 2010.

13. Trial of Abiraterone Acetate Plus LHRH-therapy Versus Abiraterone Acetate Sparing LHRH-therapy in Patients With Progressive Chemotherapy-naïve Castration-resistant Prostate Cancer (SPARE) (SPARE). https://clinicaltrials.gov/ct2/show/ NCT02077634. Accessed June 12, 2016.

14. Oken MM, Creech RH, Tormey DC, Horton J, Davis TE, McFadden ET and Carbone PP: Toxicity and response criteria of the Eastern Cooperative Oncology Group. Am J Clin Oncol 5: 649-655, 1982.

15. Reuter CWM, Morgan MA, Ivanyi P, Fenner M, Ganser A and Grünwald V: Carboplatin plus weekly docetaxel as salvage chemotherapy in docetaxel-resistant and castration-resistant prostate cancer. World J Urol 28: 391-398, 2010.

16. Gleason DF and Mellinger GT: Prediction of prognosis for prostatic adenocarcinoma by combined histological grading and clinical staging. J Urol 111: 58-64, 1974.

17. Sobin LH and Compton CC: TNM seventh edition: What's new, what's changed: Communication from the International Union Against Cancer and the American Joint Committee on Cancer. Cancer 116: 5336-5339, 2010 .

18. Huggins C and Hodges CV: Studies on prostatic cancer. I. The effect of castration, of estrogen and of androgen injection on serum phosphatases in metastatic carcinoma of the prostate. 1941. J Urol 167: 948-952, 2002.

19. Attard G, Belldegrun AS and de Bono JS: Selective blockade of androgenic steroid synthesis by novel lyase inhibitors as a therapeutic strategy for treating metastatic prostate cancer. BJU Int 96: 1241-1246, 2005.

20. Tran C, Ouk S, Clegg NJ, Chen Y, Watson PA, Arora V, Wongvipat J, Smith-Jones PM, Yoo D, Kwon A, et al: Development of a second-generation antiandrogen for treatment of advanced prostate cancer. Science 324: 787-790, 2009.

21. Perachino M, Cavalli V and Bravi F: Testosterone levels in patients with metastatic prostate cancer treated with luteinizing hormone-releasing hormone therapy: Prognostic significance? BJU Int 105: 648-651, 2010.

22. Morote J, Orsola A, Planas J, Trilla E, Raventós CX, Cecchini L and Catalán R: Redefining clinically significant castration levels in patients with prostate cancer receiving continuous androgen deprivation therapy. J Urol 178: 1290-1295, 2007.

23. Byar DP: Proceedings: The veterans administration cooperative urological research group's studies of cancer of the prostate. Cancer 32: 1126-1130, 1973.

24. Hussain M, Wolf M, Marshall E, Crawford ED and Eisenberger M: Effects of continued androgen-deprivation therapy and other prognostic factors on response and survival in phase II chemotherapy trials for hormone-refractory prostate cancer: A southwest oncology group report. J Clin Oncol 12: 1868-1875, 1994. 
25. Taylor CD, Elson P and Trump DL: Importance of continued testicular suppression in hormone-refractory prostate cancer. J Clin Oncol 11: 2167-2172, 1993.

26. de Bono JS, Logothetis CJ, Molina A, Fizazi K, North S, Chu L, Chi KN, Jones RJ, Goodman OB Jr, Saad F, et al; COU-AA-301 Investigators: Abiraterone and increased survival in metastatic prostate cancer. N Engl J Med 364: 1995-2005, 2011.

27. Ryan CJ, Peng W, Kheoh T, Welkowsky E, Haqq CM, Chandler DW, Scher HI and Molina A: Androgen dynamics and serum PSA in patients treated with abiraterone acetate. Prostate Cancer Prostatic Dis 17: 192-198, 2014.

28. Oefelein MG and Cornum R: Failure to achieve castrate levels of testosterone during luteinizing hormone releasing hormone agonist therapy: The case for monitoring serum testosterone and a treatment decision algorithm. J Urol 164: 726-729, 2000.

29. Sharifi R and Browneller R; Leuprolide Study Group: Serum testosterone suppression and potential for agonistic stimulation during chronic treatment with monthly and 3-month depot formulations of leuprolide acetate for advanced prostate cancer. J Urol 168: 1001-1004, 2002.

30. Smith MR: Obesity and sex steroids during gonadotropin-releasing hormone agonist treatment for prostate cancer. Clin Cancer Res 13: 241-245, 2007.

31. Colombel M,SymmansF, Gil S, O'Toole KM,Chopin D,BensonM, Olsson CA, Korsmeyer S and Buttyan R: Detection of the apoptosis-suppressing oncoprotein bc1-2 in hormone-refractory human prostate cancers. Am J Pathol 143: 390-400, 1993.
32. Sun M, Yang L, Feldman RI, Sun XM, Bhalla KN, Jove R, Nicosia SV and Cheng JQ: Activation of phosphatidylinositol 3-kinase/Akt pathway by androgen through interaction of p85alpha, androgen receptor, and src. J Biol Chem 278: 42992-43000, 2003.

33. Craft N, Shostak Y, Carey M and Sawyers CL: A mechanism for hormone-independent prostate cancer through modulation of androgen receptor signaling by the hER-2/neu tyrosine kinase. Nat Med 5: 280-285, 1999.

34. Antonarakis ES, Lu C, Wang H, Luber B, Nakazawa M, Roeser JC, Chen Y, Mohammad TA, Chen Y, Fedor HL, et al: AR-v7 and resistance to enzalutamide and abiraterone in prostate cancer. N Engl J Med 371: 1028-1038, 2014.

35. Egan A, Dong Y, Zhang H, Qi Y, Balk SP and Sartor O: Castration-resistant prostate cancer: Adaptive responses in the androgen axis. Cancer Treat Rev 40: 426-433, 2014.

36. Merseburger AS, Kuczyk MA and Wolff JM: Pathophysiology and therapy of castration-resistant prostate cancer. Urologe A 52: 219-225, 2013.

37. Pinski J, Xiong S, Wang Q, Stanczyk F, Hawes D and Liu SV: Effect of luteinizing hormone on the steroidogenic pathway in prostate cancer. Prostate 71: 892-898, 2011.

38. Mostaghel EA, Nelson PS, Lange P, Lin DW, Taplin ME, Balk S, Ellis W, Kantoff P, Marck B, Tamae D, et al: Targeted androgen pathway suppression in localized prostate cancer: A pilot study. J Clin Oncol 32: 229-237, 2014. 